\title{
ЛЕКСИЧЕСКИЕ АСПЕКТЫ ЯЗЫКОВОЙ ИГРЫ В РУССКОМ ЯЗЫКЕ
}

\author{
LEXICAL ASPECTS OF THE LANGUAGE GAME \\ IN THE RUSSIAN LANGUAGE
}

VOLODYMYR DUBICHYNSKYI

\begin{abstract}
AвSTRACT. Language game can take place on different language levels: phonetic, graphical, lexical-semantic, word-formative, morphological, syntax, and even pragmatics, stylistics etc. In the given article the lexical aspect of the language game is considered. Many creative language potencies are revealed most fully and brightly on the lexical-semantic level. Separate attention is paid to entimological units - lexical units which are described in the entimological dictionaries; as well as to the so called "anti-proverbs" - abnormal paremiological units.
\end{abstract}

Keywords: language game, lexical aspect, entimological units, anti-proverbs

Volodymyr Dubichynskyi, Uniwersytet Warszawski, Warszawa - Polska, v.dubichynskyi@uw.edu.pl

ORCID ID: 0000-0001-8115-7015

Язык - не игрушка. Человеческий язык - дело серьёзное. Овладев языком в детстве, человек использует этот инструмент в течение всей (!) жизни, познавая всё новые его функции и возможности. А язык раскрывается перед человеком с каждым разом своими всё более интересными сторонами.

Как и любым другим инструментом, человек не только пользуется, но и играет. А жизненный опыт показывает, что язык, в свою очередь, играет человеком: заставляет попадать в неловкие ситуации, путать и путаться, радоваться и смеяться, тосковать и плакать.

Феномен языковой игры включает в себя и языковой эксперимент, заключающийся в эксплуатации „аномалии” на фоне языковой нормы (Нина Арутюнова), и „игру на гранях языка” , обнаруживающую нереализованный и интуитивно ощущаемый говорящими потенциал языковой системы (Борис Норман), и языкотворчество, связанное с обновлением имеющегося арсенала готовых номинативных единиц (Владимир Санников) [Гридина 2013: 14]. 
Комическое - это такое отклонение от нормы, которое удовлетворяет двум следующим условиям: 1) приводит к возникновению двух содержательных планов (от исходной точки совершается внезапный переход к конечному результату, резко отличающемуся от исходной точки); 2) ни для кого в данный момент не опасно, а для воспринимающих шутку даже приятно, поскольку это отклонение вызывает в них, лишенных этого недостатка, чувство превосходства или же (в случае „интеллектуальных” шуток) довольство по поводу исправности их интеллекта [Санников 1999: 22].

Универсальность человеческого языка подтверждает, что игра может осуществляться на различных языковых уровнях: фонетическом, графическом, лексико-семантическом, словообразовательном, морфологическом, синтаксическом и даже на уровне прагматики, стилистики и т.п.

В данной статье нас интересует лексико-семантический уровень языка. Именно на этом уровне в наиболее полном и ярком виде раскрываются многие потенции языка.

Приведём несколько примеров, описывающих тематику языковой игры на лексико-семантическом уровне языка (примеры взяты из широко представленных интернетовских источников):

\section{1) обыгрывание компонентов значения слова (компонентный анализ)}

- Всех нас хранит Господь. Но срок хранения у всех разный.

- - Вам не трудно сделать мне, пожалуйста, кофе с пенкой?

- Да раз плюнуть...

- - А вы-то сами, Соломон Абрамович, откуда будете?

- Да откуда угодно, Фима, хоть из рюмок, хоть из стаканов. Вы наливайте!

\section{2) изменение значения слова с точки зрения актуального члене- ния предложения}

Задело - за дело.

И дико мне - иди ко мне.

Покалечилась - пока лечилась.

Мы женаты - мы же на ты.

Ты жеребенок - ты же ребенок.

Несуразные вещи - несу разные вещи.

Ему же надо будет - ему жена добудет.

Надо ждать - надо ж дать.

\section{3) омонимия}

- Объявление на одесском перекрёстке: „Граждане! Не переходите улицу на тот свет!”

• „Ложь во спасение” - это неправильно. Правильно - „клади”. 
- Синдром лёгкого недомогания развивается у молодых девушек, которых никто не домогается.

- Благополучие врача-отоларинголога держится на соплях.

- Доходы офтальмологов растут на глазах.

- В Москве недорогую квартиру можно снять только на фотоаппарат.

- На экзамене по литературе:

- Что вы можете сказать о героине?

- Героин - мощная вещь. А почему вы спрашиваете?

- В порту на Одесской таможне таможенник спрашивает у старого еврея:

- Откуда прибыли?

- Какие прибыли, что вы? Одни убытки...

- Менделеев долго доказывал своей жене, что на первом месте должен стоять водород, а не жена и дети.

- Меня деньги не волнуют! Они меня успокаивают.

\section{4) паронимия}

А я понял, почему тестя называют тестем. Потому что он тестировал предыдущую версию твоей жены.

Жизнь даётся лишь раз, а удаётся ещё реже.

Живу в достатке: всё достало...

\section{5) синонимия/антонимия}

- - Роза! У тебя лишний вес!

- Это не лишний. Это запасной!

- Вы никогда не задумывались о том, что антоним к слову „антоним” - это „синоним"?

- - Папа, а слова ТРУДНО, СЛОЖНО и ТЯЖЕЛО - это синонимы?

- Нет, сынок. ТРУДНО - отказаться от предложения выпить. СЛОЖНО - рассчитать свою оптимальную дозу. А ТЯЖЕЛО - это уже утром.

\section{6) оксюморон}

Старый новый год

Принуждение к миру

Детская пластмассовая железная дорога

Свежие консервы

Незаконные бандформирования

Холодный кипяток

Сухое вино

Миротворческие войска

Истинная правда

Да нет наверное

Наверное, точно

Начинают заканчиваться

Деревянный стеклопакет

У пациента сильная слабость 
Убить насмерть

Пойду съезжу в магазин

Предельно допустимая норма

Смертная казнь

Федеральная служба по контролю за оборотом наркотиков

В определённой степени лексический аспект языковой игры проявляется также и в лексической стилистике, и в эвфемизмах, и в диалектизмах, жаргонизмах, макаронической речи, в каламбуре и даже в таком новом феномене, как демотиваторы.

Представленная тематика довольно подробно описана в лингвистической литературе двух последних десятилетий [см. Киклевич 2006; Кронгауз 2006; 2007; Норман 2004; 2006; Санников 1999; Седов 2005 и др.].

В данной статье хотелось бы особо остановиться на таком лексическом феномене как энтимологизмы, описанные в энтимологическом словаре [Норман 1987], который в своеобразной форме представляет языковую игру на лексико-семантическом уровне.

Авторами энтимологического словаря Владимиром Карповым и Борисом Норманом предложена оригинальная методика заведомо ложных, неправильных толкований русских слов, например (здесь и далее примеры подаются по Энтимологическому словарю [см. Норман 2006: 283-337]):

спица - соня, любительница поспать;

пролетарий - аэроплан;

оторва - 1. квитанция; 2. пуговица на одной нитке.

Энтимологии - это своего рода семантизация лексической единицы в условиях языковой игры. Следует заметить, что мы имеем дело с лексикографической игрой, где „настоящие” заголовочные единицы описываются „ненастоящими”, комическими толкованиями, основанными на различных языковых явлениях.

Прежде всего речь идёт о явлении народной этимологии,

когда человек определяет происхождение слова (точнее, его словообразовательную историю: какой признак лежит в основе названия?), опираясь на случайное формальное сходство с другим словом. Например, почему подушка называется подушкой? Потому что она „под ухом”. С аналогичным процессом мы имеем дело и в „энтимологиях" типа жрец - „тот, кто много жрёт”, или днище - „долгий день". Поэтому можно, несколько огрубляя, определить „энтимологизирование" как языковую игру, в которой народная этимология принимает форму семантизации [Норман 2006: 261-262].

Народная этимология предполагает сближение/смешение слов в речи такими носителями языка, которые плохо овладели его нормами. 
А энтимологии как элементы языковой игры „заставляют рассматривать любой акт языкотворчества как преднамеренный, что исключает возможность случайных столкновений языковых единиц, приводящих к приращению смысла" [Фатеева 2016: 17].

Нам хотелось бы представить несколько видов энтимологизированной народной этимологии:

1) народная этимология, представляющая собой энтимологизированное актуальное членение звукового ряда, например:

интерлюдия - многонациональный коллектив (интер+люди);

барбос - хозяин бара (бар+бос);

кожемяка - массажист (кожа+мять);

2) народная этимология, основанная на „игровом” толковании иностранных заимствований, например:

гастрит - улица площадью 1 га (га+стрит);

портсигар - Гаванна (порт+сигар);

лазер - альпинист (лазить ссуффикс деятеля -ер);

3) суффиксальные энтимологизмы, которые показывают полнозначность и типичность широко употребляющихся в русском языке суффиксов как исконного, так и иностранного происхождения, например:

бандаж (милиц.) - количество преступных группировок (банда + французский суффикс -аж, показывающий совокупность чего-л.);

вареник - ученик повара (варить+ник);

ариец - действующее лицо в опере (ария+ец);

4) собственно словообразовательная семантизация, например:

деньжонки (праздн.) - Восьмое марта (день+жена);

договор - человек, крадущий породистых собак (вор+дог);

богемистика - религиозно-мистическое учение (бог+мистика);

5) народная этимология, основанная на иной семантизации, связанной с обыгрыванием многозначности слова, например:

жалованье - петиция (обыгрывается значение слова жаловаться на кого-л.); великодушие - многолюдность (душа в значении „человек”);

леденец - мороз (лёд в значении „что-то очень холодное”).

Толкование энтимологизмов основано также на других лексико-семантических категориях: омонимии, паронимии, жаргонной (просто- 
речной, разговорной) и ономастической лексике, а также в аббревиатурах. Попытаемся отыскать в словаре иллюстрирующие доказательства на каждую из этих позиций.

\section{Омонимия}

везение - транспортировка (обыгрываются омонимы везёт I кого-л. на транспорте и везёт II в чём-ц.);

безбрачие - качественная работа (обыгрываются омонимы брак I „супружество” и брак II „изъян, недоделка";

дача (юр.) - взятка (омографы/омоформы дача I „загородный дом" и дача II от слова давать).

\section{Паронимия}

дорожить (трансп.) - ездить, путешествовать (обыгрывание паронимов дорогой/ дорога);

хлопоты - аплодисменты (паронимы хлопать/хлопотать);

винодел - нарушитель порядка (паронимы вино/вина).

\section{Жаргонные (просторечные, разговорные) энтимологизмы}

закладка - доносчица (от просторечного значения слова закладывать „доносить, сообщать");

пойло - сольфеджио, вокальное упражнение (жаргонное слово пойло от слова пить обыгрывается со словоформой пой от глагола петь)

буханка (жарг.) - алкоголичка (имеется в виду жаргонное слово бухать в значении „пить алкоголь").

Ономастические энтимологизмы (благодаря языковой игре в толкованиях имена собственные приобретают нарицательные значения)

Осип - простуженный, больной ОРЗ (аллюзия с осипнуть);

Максимилиан - мультимиллиардер (аллюзия с максимум);

Ной - нытик, зануда (аллюзия с ныть).

Аббревиатурные энтимологизмы (комический эффект достигается в случае, когда аббревиатуры случайно и/или неожиданно воспринимаются и толкуются как полнозначные слова)

дофин - доктор филологических наук;

универсам - умелец.

Большую роль в энтимологическом словаре играют ассоциации. Ассоциативный принцип человеческого мышления отражает систему смысловых связей в мозгу. Следует учесть, что энтимологизмы удачны 
только тогда, когда ассоциации устойчивы, т.е. отображают сознание определённого языкового коллектива, и в то же время неожиданны, другими словами, как-то непривычно, неожиданным образом просвечивают семантическую структуру производного слова. Например:

попадья - результативная баскетболистка (неожиданная ассоциация с глаголом nопасть);

Навуходоносор (белор.) - осведомитель, стукач (имя собственное древнеегипетского фараона неожиданно ассоциируется с доносительством, с тайным нашёптыванием на ухо);

ухажёр - любитель рыбного супа (слово ухаживать неожиданным образом ассоциируется со словами уха и жрать/жёр).

Эффект языковой игры достигается на основе нестандартности (нетривиальности) ассоциативных сближений: „Осознание парадоксальности, условности (даже ошибочности) установленной ассоциативной связи создаёт поле для языковой игры" [Гридина 2016: 68].

В энтимологическом словаре описывается интересное явление изменения внешней формы лексической единицы путём перекручивания, переворачивания буквосочетаний, слогов, частей слова и т.п., что и производит искомый авторами комический эффект:

ландо - хошоро, доворогились (методом перевёртыша построены не только заголовочный энтимологизм, но и само толкование: хорошо, договорились);

баркас - то же, что карбас (комизм достигается тем, что в словаре не разъясняется, что же такое карбас);

сикомор - яд для сикофанта (от морить каких-то сикофантов).

Один из авторов словаря Б.Ю. Норман отмечает типичные недостатки словарей, которые выпячиваются и высмеиваются в кривом зеркале Энтимологического словаря. Это:

во-первых, недостаточная системность в описании лексики. Каждое слово здесь изолировано, само по себе, без учёта других слов и других толкований. Например, КЛУБНИКА объясняется как „уборщища в клубе”, КЛУБНИЧНЫЙ - как „картофельный”;

во-вторых, типичным лексикографическим „проколом” является так называемый круг в толковании, когда одна лексема толкуется через другую, а та, в свою очередь, возвращает читателя к первой: круг замыкается. Например, НУЖНИК - то же, что ТРЕБНИК; ТРЕБНИК - то же, что НУЖНИК;

в-третьих, энтимологическое толкование слегка зашифровывает значение слова. Например, энтимология слова СКЛАДЕНЬ - „складной нож” плоха, лучше: „перочинный нож”; ОШАЛЕТЬ - купить в магази- 
не пуховый платок (не шаль!); ХОЛЕРИК - инфекционный больной (не больбной холерой!). Получается, что, осваивая „энтимологии”, читатель одновременно активизирует, оживляет заложенные в его сознании системные лексические связи [Норман 2006: 273-275].

И хотя сам Норман называет своё произведение „своего рода антисловарём” [Норман 2006: 273], надо заметить, что определённые лексикографические черты чётко выражены в подаче, прежде всего, многозначности заголовочных единиц и в словарных пометах.

Многозначная семантическая структура заголовочной лексемы представлена в словаре довольно регулярно. Например:

тяжба - 1. соревнование штангистов (от тяжёлая атлетика); 2. влечение (от тяHymb);

скорняк - 1. расторопный официант; 2. (железнодор.) экспресс (и первое, и второе значения - от слова скорый);

пай-мальчик - 1. новый член жилищного кооператива (от пай „взнос”); 2. молодой акционер; 3. ученик лудильщика (от паять).

Лексикографические пометы полностью поддерживают пародийность и комизм словаря. И хотя присловные пометы носят, как правило, нетрадиционный, случайный характер, они являются частью толкований: продолжают, расширяют, уточняют семантизацию заголовочного слова. Например:

мазь (спорт.) - серия промахов (от просторечного глагола мазать „промахиваться, не попадать");

халатность (больнич.) - обеспеченность медперсонала халатами;

дышло (физкульт.) - лёгкие (от глагола дымать).

Зачастую к лексико-семантическому уровню относят паремиологические единицы (ПЕ), в которых, благодаря сочетаемостным потенциям лексических единиц, язык раскрывает свои творческие возможности.

Готлоб Фреге писал: „Необходимо всегда учитывать полное предложение. Только в нём слово обладает подлинным значением. [...] Слова обозначают нечто только в контексте предложения" [Фреге 2008: 196, 198]. Лингвистический закон небуквального употребления слов подтверждает, что значения лексических единиц сами находят себе ситуации, в которых „хотят жить”.

В последнее время среди ПЕ лингвисты выделяют такое явление языковой игры как „антипословицы” - своего рода аномальные паремиологические единицы, представляющие собой осмеяния, переделки, выворачивания наизнанку традиционных пословиц и поговорок. Например, 
Лысый пешему не конный; Не имей сто рублей, а имей сто врагов; Аппетит приходит во время еды, а отравление - после; Любишь кататься - так катись к чертовой матери; Пришел, увидел, отойди - дай другим посмотреть. Речь не идет о „неправильных" собственно фразеологизмах (например, легок на поминках), а об аномальных - с точки зрения традиционной лингвистики - пословицах, поговорках и крылатых словах.

Аномальные ПЕ существуют для достижения комического эффекта и трудно определить, с какими языковыми единицами мы имеем дело. Намеренно допускаемая неправильность относительна с точки зрения традиционности и нормативности. Сегодняшняя аномальность рассматриваемых паремий завтра может стать нормативностью. Возможно, через некоторое время для нас нормальным будет не Лучше один раз увидеть, чем сто раз услышать, а Лучше один раз потрогать, чем сто раз увидеть; не Скажи мне, кто твой друг, и я скажу, кто ты, а Скажи мне, кто я, и я скажу, кто ты.

Вот как объясняет механизм использования лексических единиц в „антипословицах" Максим Кронгауз:

В чём суть такой такой игры? Предполагается, что собеседники должны опознать цитату и понять, ради чего её исказили. Это напоминает двойное подмигивание. Первый раз: „Ну, что, узнал?”. И второй: „Смотри, что я с этим сделал, сейчас будет смешно!". Само клише, таким образом, привлекает внимание и одновременно является тестом на „свой-чужой”, а игра с ним по замыслу говорящего должна вызвать юмористический эффект (что, впрочем, не всегда удаётся). Смыслы речевого клише и его искажения как бы сталкиваются, и вместо одной линейной фразы возникает многомерный текст. Разрушитель цитаты вступает с её автором в короткую и комическую дискуссию [Кронгауз 2007: 142].

Попытаемся классифицировать среди аномальных паремиологических единиц (так называемых „антипословиц") следующие типы (здесь и далее примеры антипословиц взяты из словаря Антипословищы русского народа [см. Вальтер, Мокиенко 2005]:

1) ПЕ-определения (своего рода шутливые толкования слов-понятий наивной картины мира):

Воздух - это шарик, с которого содрали кожу.

Жизнь - штука опасная, но если вовремя умереть, многих болезней можно избежать.

Страховой агент - это человек, который желает нам добра после зла.

Трезвый - это хорошо выспавшийся пьяный.

Улыбка - понятие растяжимое.

Умными мы называем людей, которые с нами соглашаются.

Чистоплотность - это чисто масса, делённая на чисто объём. 
2) высказывания из жизненного опыта (меткие народные наблюдения в виде кратких „пословично-поговорочных” единиц, как правило, и оптимистичные, и пессимистичные):

Гонят в шею обычно пинками под зад.

Если не сядет самолет, то сядет техник.

Кто первый украл, тот и автор.

Лучше пузо от пива, чем горб от работы.

Полная ясность бывает лишь в пустой голове.

Скромность украшает, но оставляет голодным.

Хорошо там, где нас нет, но плохо, что нас нет там, где хорошо.

3) паронимо-омонимичные ПЕ (языковая игра, основанная на заменах паронимов и омонимов, входящих в данные паремиологические единицы):

В столовой готовят пищу для жалоб.

Искусство требует жратвы!

Истина - в вине; осталось узнать только в чьей.

Не йоги горшки обжигают.

Предприниматели всех стран, налогооблажайтесь!

Толстячок - а приятно.

Язык до киллера доведет.

4) „составные” ПЕ-контаминации (состоящие из различных, по-новому сочетающихся частей или паракдоксально сочетающихся полных традиционных пословиц и поговорок):

Бабу с возу могила исправит (Ср. Баба с возу - кобыле легче).

Без труда и кашу маслом не испортишь (Ср. Без труда не вытянешь и рыбку из пруда).

Дарёному коню кулаками не машут (Ср. Дарёному коню в зубы не смотрят, а также После драки кулаками не машут).

Любишь кататься - имей сто рублей (Ср. Любишь кататься - люби и саночки возить, а также Не имей сто рублей, а имей сто друзей).

Один в поле хуже татарина (Ср. Один в поле не воин, а также нежданный гость хуже татарина).

Слово не воробей, упадет с воза, не вырубишь и топором (Ср. Слово не воробей, вылетит - не поймаешь, а также Что с воза упало, то пропало, а также Что написано пером, не вырубишь и топором).

Тише едешь - кобыле легче (Ср. Тише едешь - дальше будешь, а также Баба с возу - кобыле легче).

5) ПЕ-перестановки (элементы словосочетания, пословицы или поговорки меняются местами, создавая комический эффект, в том числе меняются грамматические характеристики): 
Бронетёмкин Поносец (Ср. Броненосец „Потёмкин”).

Добро всегда побеждает зло. Так и неясно, кто кого побеждает.

Дурные ноги голове покоя не дают (Ср. От дурной головы нет ногам покоя).

Шпион - находка для болтуна (Ср. Болтун - находка для шпиона).

Не пожелай ближнему жены своей (Ср. Не пожелай жены ближнего своего).

Не откладывай на сегодня то, что можно сделать завтра (Ср. Не откладывай на завтра то, что можно сделать сегодня).

Тише будешь, дальше уедешь (Ср. Тише едешь, дальше будешь).

\section{6) паремии-сравнения}

Время как шкаф: всегда можно найти, чем его наполнить.

Девушка как парашют: всегда лучше иметь запасной.

Лучше гипс и кроватка, чем гранит и оградка.

Лучше иметь синицу в руках, чем утку под кроватью.

Лучше красиво повеситься, чем плохо жениться.

Одни копят, словно должны жить вечно, другие тратят, словно тотчас умрут.

Чем дальше в лес, тем толще партизаны.

7) ПЕ-клише (выражения, в которых стереотипные клишированные словосочетания употребляются в шутливом контексте)

Выбранный президент обмену и возврату не подлежит.

Гася свет, не забывайте уходить.

Каждый живёт по способностям выдумать себе потребности.

Мойте руки вместо еды.

Не будь парикмахеров, нам пришлось бы самим рвать на себе волосы.

Премия греет, но мне не светит.

У строителей воздушных замков всегда хватает материала.

Совершенно очевидна ярко выраженная афоризмизация аномальных паремий. Ироничные высказывания в виде „перекрученных мудростей" становятся застывшими сентенциями нового современного мировидения - национальной картины мира послеперестроечного поколения. Изворотливым трудолюбием и доброй разухабистостью народной мудрости достигается многозначная глубина мысли и по-новому структурированная слаженность языковых единиц.

Сегодняшняя иронизация над хрестоматийной мудростью выглядит „неправильностью”, но завтра, может быть, она станет традиционностью приходящего времени. Аномальные паремиологические единицы в зеркале языковой игры, воспринимаемые сегодня как потрясение традиций и норм, приведут нас, возможно, к новому ироничному мировоззрению в будущем. Языковая практика показывает, что сегодня русский язык постепенно изменяет национальную картину мира. Может быть, использование лексических единиц аномальных паремий представляет 
новое „игровое” (ироничное, комическое и т.п.) мировоззрение нового поколения?

А то, ка́к изменяется и/или может измениться национальная картина мира и каковы её основные черты, ещё предстоит описать лингвистам, литературоведам и культурологам будущего на основе осознания аномальных лексических/фразеологических единиц и общих лексико-семантических особенностей языковой игры в русском языке.

\section{Библиография}

Вальтер Х., Мокиенко В. М. 2005. Антипословицы русского народа, Санкт-Петербург: Нева.

Гридина Т. А. 2013. К истокам вербальной креативности: творческие эвристики детской речи, [в:] Т. А. Гридина (ред.), Лингвистика креатива-1, Екатеринбург: Уральский государственный педагогический университет, с. 5-58.

Гридина Т. А. 2016. Игровой потенциал слова (по данным ассоциативного словаря), [в:] Т. М. Воронина (ред.), Новая Россия: традиции и инновации в языке и науке о языке, Москва-Екатеринбург: Кабинетный учёный, с. 56-69.

Киклевич А. К. 2006. Лингвисты шутят, Москва: Флинта-Наука.

Кронгауз М. А. 2006. Семантика. Задачи, задания, тесты, Москва: Академия.

Кронгауз М. А. 2007. Русский язык на грани нервного срыва, Москва: Языки славянских культур.

Норман Б. Ю. 1987. Язык: знакомый незнакомец, Минск: Вышэйшая школа.

Норман Б. Ю. 2004. Русский язык в задачах и ответах, Минск: Новое знание.

Норман Б. Ю. 2006. Игра на гранях языка, Москва: Флинта-Наука.

Санников В. 3. 1999. Русский язык в зеркале языковой игры, Москва: Языки русской культуры.

Седов К. Ф. 2005. Психолингвистика в анекдотах: учебное пособие, Москва: Лабиринт.

Фатеева Н. А. 2016. Языковая креативность: подступы к теме, [в:] Н. А. Фатеева (отв. ред.), Труды Института русского языка им. В. В. Виноградова, вып. VII, Москва: Институт русского языка им. В. В. Виноградова, с. 14-28.

Фреге Г. 2008. Логико-философские труды, Новосибирск: Сибирское университетское издательство. 